fournal of Medical Genetics (1973). 10, 1.

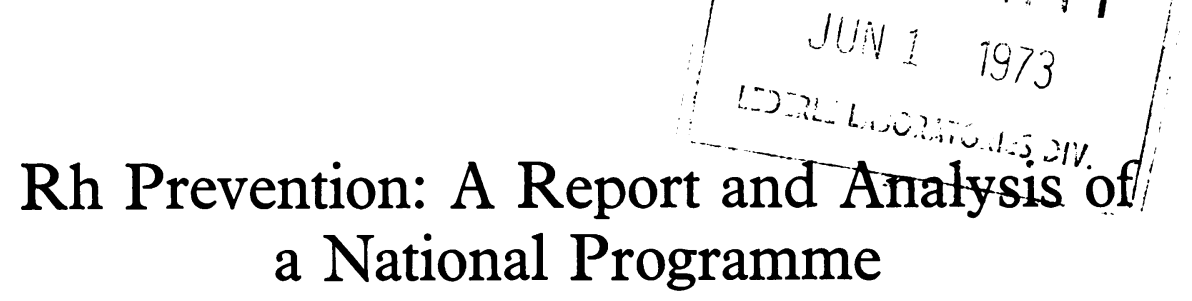

\author{
J. EKLUND and H. R. NEVANLINNA
}

Finnish Red Cross Blood Transfusion Service, Helsinki 31, Finland

\begin{abstract}
Summary. A nation-wide Rh prevention programme was started in Finland in 1969. Before that, a control series of approximately $1000 \mathrm{Rh}$-negative mothers giving birth to an $\mathrm{Rh}$-positive child was collected to estimate the number of mothers with antibodies at either three, six, or nine months post partum. During the threeand-a-half year period altogether 14,980 Rh-negative patients were given $250 \mu \mathrm{g}$ of anti-D immunoglobulin prepared from Finnish raw material in the Central Laboratory of the Dutch Red Cross. Out of those treated before the end of June 1972, $12,720(97 \%)$ were tested four to six months post partum. Seventeen or $0 \cdot 13 \%$ had detectable antibodies; in five of them the infant was ABO incompatible. The number of protected mothers with a subsequent $\mathrm{Rh}$-positive infant was $1017 ; 10$ had formed antibodies before the delivery of the second child.

The risk of primary immunization initiated during a single pregnancy was estimated to be $0.35 \%$. In addition, there was approximately a $0.60 \%$ risk of forming antibodies by the next Rh-positive pregnancy.

The effect of prevention on the prevalence of haemolytic disease was calculated and compared with observed figures.
\end{abstract}

The preventive effect of the administration of anti-D immunoglobulin is well documented. (Combined study from Centres in England and Baltimore, 1971; WHO Scientific Group, 1971; Woodrow et al, 1971; Clarke, 1972; Clarke and McConnell, 1972.) The failure incidence varies between 0.0 and $0.6 \%$ (Schneider, 1971). The evidence is mainly derived from comparisons with a large series of post-delivery control samples. The possible boosting effect of an additional Rh-positive child during the next pregnancy has so far only been studied in rather limited series (Woodrow, 1970; Schneider, 1971; Woodrow et al, 1971). With a few exceptions (Zipursky and Israels, 1967; Godel et al, 1968; Buchanan et al, 1969; V. J. Freda and J. G. Gorman in Fournal of Reproductive Medicine, 1971) the reports pay little or no attention to the group of patients excluded from prevention due to antibody formation before the delivery.

The purpose of this report is to present the results of a national $\mathrm{Rh}$ prevention programme including

\footnotetext{
Received 23 November 1972.
}

more than 12,000 patients followed up four to six months after delivery and more than 1000 of these who, after the administration of anti-D immunoglobulin, gave birth to another Rh-positive child. The results were analysed in order to compare the observed with the expected risk of immunization and to predict the effect of prevention on the incidence of haemolytic disease in the future. Other details of possible theoretical and practical importance are discussed.

\section{Control Series}

The control series comprised $1707 \mathrm{Rh}$-negative mothers delivered at two large lying-in hospitals in Helsinki between 1 October 1967 and 31 December 1968. All those without detectable antibodies at delivery who gave birth to an $\mathrm{Rh}$-positive child were asked to give a follow up sample three, six, and nine months after delivery. The participation rate was good at 93,90 , and $85 \%$. D antibodies were found in 35 out of 1012 mothers, all but four of the antibodies being already present at three months. 
TABLE I

CONTROL SERIES. RESULTS OF TESTS FOR ANTIBODIES 3, 6, OR 9 MONTHS AFTER DELIVERY

\begin{tabular}{l|c|c|c}
\hline $\begin{array}{c}\text { ABO } \\
\text { Constellation } \\
\text { Mother/Child }\end{array}$ & Immunized & Not immunized & Immunized ( $\%$ \% \\
\hline $\begin{array}{l}\text { Compatible } \\
\text { Incompatible }\end{array}$ & 34 & 758 & 4.3 \\
\hline Total & 1 & 219 & \\
\hline
\end{tabular}

No additional immunized mothers were found in the nine-month test. The overall risk of immunization was $3.5 \%$ or $4.3 \%$ if the $\mathrm{ABO}$ incompatible pairs are excluded (Table I). This is somewhat smaller than reported elsewhere; however, the collaborative German study reports an incidence of anti-Rh four to seven months after delivery of $3 \cdot 8 \%(89 / 2330)$ and the Dutch figure is $5.2 \%$ (Schneider, 1971). Neither of these is significantly different from ours.

\section{Protected Series}

Anti-D Immunoglobulin. The collection of plasma with a minimum titre of $1: 256$ was started in 1967 and fractionated in pools of 100 to 250 litres in the Central Laboratory of the Dutch Red Cross Blood Transfusion Service. The plasma was collected using double plasmapheresis from a group of some 40 volunteers: recently delivered mothers with erythroblastotic babies, re-stimulated and sterilized mothers, naturally immunized, and deliberately immunized male volunteers. The amount of plasma collected yearly was approximately 300 litres with a Coombs titre of $1: 1000$ in the pool. The specific content of anti-D was kindly determined by Dr Hughes-Jones in the WHO International Reference Centre for the Use of Anti-D $\left(R h_{o}\right)$ in the Prevention of $R h$ Sensitization, London. In order to expand the programme as quickly as possible 2000 doses of anti-D immunoglobulin was purchased from Kabi, Stockholm, and used during 1969. The dose of both the preparations throughout the series was $250 \mu \mathrm{g}$ administered intramuscularly within 72 hours of delivery of an Rh-positive child irrespective of the $\mathrm{ABO}$ constellation.

Samples. At delivery, double clotted samples were collected from the mother and cord. One pair was investigated in the local hospital where the ABO group and $\mathrm{Rh}$ type was determined. The other pair of samples was sent to our laboratory where the following tests were made: $\mathrm{ABO}$ grouping with known sera and cells, Rh typing with Löw's technique, testing negative or weak reactions with Coombs technique, screening of maternal antibodies with papain and Coombs techniques, and direct Coombs test on the cord blood. The presence of antibodies or deviation in the other results was immediately reported to the hospital.

The protected mothers were informed both verbally and in writing and asked to provide a follow up sample at the nearest ante-natal clinic after four months and not later than six months. Those who neglected to give the sample were contacted twice and if necessary the personnel of the clinic or the health authorities were asked to trace the mother. The samples were tested in our laboratory for the presence of antibodies, again using both papain and Coombs techniques.

Rate of Participation. The programme, when started on 1 January 1969, included all the larger lying-in hospitals and maternity wards of the country and was expanded to the smaller ones during the summer of the same year. To estimate the participation rate the frequencies of $\bar{D}$ (and $\bar{d}$ ) in the population were calculated. This is the same as the proportion of $\mathrm{D}$-positive children in all the children born, ie, $13,540 / 20,587$ or 0.6577 . The figures include the children born to immunized mothers who delivered during the same period 614 $\mathrm{Rh}$-positive and $108 \mathrm{Rh}$-negative babies, respectively. In the general population the $\mathrm{D}$-negative group represents $11.72 \%\left(0.3423^{2}\right)$ which is somewhat less than a recent calculation from frequencies obtained from a weighted sample of nearly 6000 conscripts, ie, $12.28 \%$. The total number of deliveries, that of calculated $\mathrm{Rh}$-negative mothers with $\mathrm{Rh}$-positive babies and the protected mothers are given in Table II.

TABLE II

PARTICIPATION RATE IN ANTI-D PREVENTION

\begin{tabular}{l|c|c|c|c}
\hline \multicolumn{1}{c|}{ Year } & Total Births & $\begin{array}{c}\text { Expected } \\
\text { D - /D }+\end{array}$ & $\begin{array}{c}\text { Observed } \\
\text { (treated) }\end{array}$ & $\%$ \\
\hline 1969 & 67,500 & 5200 & 3726 & $71 \cdot 6$ \\
1970 & 64,400 & 4960 & 4346 & 87.6 \\
1971 (first half) & 61,500 & 4739 & 4476 & 94.5 \\
1972 (finn & 30,000 & 2312 & 2368 & 100.0 \\
\hline
\end{tabular}

It should be remembered that, apart from negligence, there is a group of mothers who are not protected because of the presence of antibodies at delivery. In addition, protection was omitted in an unknown number of cases due to sterilization or some other reason.

Blood Typing and Clerical Errors. The double investigation made it possible to register the results that differed in the local hospital and in our 
TABLE III

BLOOD TYPING AND CLERICAL ERRORS

\begin{tabular}{|c|c|c|c|c|c|c|}
\hline & \multicolumn{6}{|c|}{ Test Results } \\
\hline & Hospital Sample & $\begin{array}{l}\text { Sample } \\
\text { Tested by our } \\
\text { Laboratory }\end{array}$ & 1969 & 1970 & 1971 & $\begin{array}{c}1972 \\
\text { (first half) }\end{array}$ \\
\hline Mother:'child & $\begin{array}{l}\mathbf{R h}-\mathbf{R h}- \\
\mathbf{R h}-\mathbf{R h}+ \\
\mathbf{R h}-\mathbf{R h}+\end{array}$ & $\begin{array}{l}\mathbf{R h}-/ \mathbf{R h}+ \\
\mathbf{R h}-/ \mathbf{R h}- \\
\mathbf{R h}+/ \mathbf{R h}+\end{array}$ & $\begin{array}{r}116 \\
33 \\
81\end{array}$ & $\begin{array}{r}134 \\
42 \\
66\end{array}$ & $\begin{array}{l}96 \\
36 \\
38\end{array}$ & $\begin{array}{l}24 \\
24 \\
27\end{array}$ \\
\hline \multicolumn{2}{|c|}{$\begin{array}{l}\text { Discrepancy in } A B O \text { grouping } \\
\text { Mothers } \\
\text { Children }\end{array}$} & & $\begin{array}{r}9 \\
76\end{array}$ & $\begin{array}{r}4 \\
68\end{array}$ & $\begin{array}{r}6 \\
86\end{array}$ & 31 \\
\hline \multicolumn{2}{|c|}{$\begin{array}{l}\text { Total number of discrepancies } \\
\text { Total number of samples } \\
\text { Errors }\left(\begin{array}{l}0 \\
0\end{array}\right)\end{array}$} & & $\begin{array}{r}315 \\
12,224 \\
2 \cdot 6\end{array}$ & $\begin{array}{r}314 \\
15,032 \\
2 \cdot 1\end{array}$ & $\begin{array}{r}262 \\
14,734 \\
1 \cdot 8\end{array}$ & $\begin{array}{l}109 \\
7934 \\
1 \cdot 4\end{array}$ \\
\hline
\end{tabular}

laboratories. The standards of the hospitals varied greatly, especially at the beginning of the survey and in small hospitals with limited practice in blood group serology. Table III shows how the standard has clearly improved during the three and a half years of the protection programme.

Failures. In the broader sense failure refers to all $\mathrm{Rh}$-negative mothers who formed antibodies during the programme. From the point of view of both mother and the community it is immaterial whether antibodies are formed after the administration of anti-D immunoglobulin or before. The Canadians and the Australians have already paid attention to both groups (Zipursky and Israels, 1967; Buchanan et al, 1969; Bowman, 1970; N. G. Davey in fournal of Reproductive Medicine, 1971); however, in many series little or no interest has been devoted to the group of mothers in whom antibodies were present before anti-D immunoglobulin was administered. In protected mothers there are two known possibilities: the failure is detected either by demonstration of antibodies in the post-delivery sample or during the next pregnancy with an $\mathrm{Rh}$ positive fetus.

Failures Observed in Post-delivery Testing. The failures are presented in Table IV which gives the total number of treated mothers who have been tested. It reflects the excellent cooperation of both the mothers (including hundreds who had emigrated to Sweden) and the welfare staff.

Failures Observed During the Next Pregnancy. By 30 June 1972, 1027 treated mothers in all had given birth to one or, in rare cases, two subsequent $\mathrm{Rh}$-positive children. Table $\mathrm{V}$ reveals that 10 patients developed antibodies, three of them before the 30th and two after the 37th week of gesta-
TABLE IV

RESULTS OF TESTS FOR ANTIBODIES 4-6 MONTHS AFTER DELIVERY IN THE TREATED GROUP*

\begin{tabular}{l|c|c|c}
\hline $\begin{array}{c}\text { ABO } \\
\text { Constellation }\end{array}$ & Immunized & Not immunized & Immunized (\%) \\
\hline Compatible & 12 & 9557 & 0.13 \\
Incompatible & 5 & 3146 & 0.16 \\
\hline Total & 17 & 12,703 & 0.13 \\
\hline
\end{tabular}

* Total number of treated mothers-14,980.

TABLE V

FAILURES. RESULTS OF TESTS FOR ANTIBODIES AT THE END OF 1027 SECOND OR LATER Rh-POSITIVE PREGNANCIES

\begin{tabular}{l|c|c} 
ABO Constellation & Immunized & Immunized $(0)$ \\
\cline { 1 - 2 } Compatible & 8 & \\
Incompatible & 2 & 1 \\
Total & 10 & 1
\end{tabular}

tion. The late appearance of the antibodies indicates that not all the mothers were primed, but were more likely to have been primarily immunized during this pregnancy and thus belong to the next group of failures.

Failures Due to Primary Immunization Initiated During Pregnancy. As stated before, this group is omitted from most series because it never received anti-D immunoglobulin. The group is a mixed one representing different mechanisms of immunization. The number of mothers who form antibodies before delivery can be estimated from the primiparae; it was 26 out of 7467 or $0.35 \%$ (Table VI). As the primiparae represent approximately one half of the total series, the number of 
TABLE VI

FAILURES. Rh-NEGATIVE MOTHERS WITH ANTIBODIES AT DELIVERY*

\begin{tabular}{l|c|c}
\hline & Mothers with Antibodies & Total \\
\hline Primiparae & 26 & 7467 \\
Multiparae & 80 & 7513 \\
\hline Total & 106 & 14,980 \\
\hline
\end{tabular}

* No antibodies detected during pregnancy.

multiparae immunized by a single pregnancy before delivery should be of the same magnitude, which doubles this group to approximately 50 mothers. That only one quarter of all the immunized women (26 out of 106) are primiparae indicates that immunization in the rest or in more than 50 cases must depend on the effect of two Rh-positive pregnancies. As protection will in future cover all pregnancies at risk, this group will decrease and finally disappear. The total failure rate has three components. The first is among those mothers who formed antibodies within six months of the post-partuminjection of anti-D immunoglobulin in this series $(0.13 \%)$. The second comprises those who formed antibodies by a single pregnancy before the delivery $(0.35 \%)$. The third group consists of the treated mothers who started the next Rh-positive pregnancy in a primed state because of a partially suppressed immune response. As the total group of 10 includes those who formed antibodies by a single pregnancy before delivery $(0.35 \%)$ the risk of a secondary response is around 0.6 or $0.7 \%$. This brings the total failure rate up to approximately $1 \cdot 15 \%$.

\section{Mothers with Weak Antibodies at Delivery Treated with Anti-D Immunoglobulin}

There were altogether 46 mothers with weak antibodies detected only with the papain technique at delivery but not in the routine pre-delivery samples. Table VII gives the result of testing four to six months after delivery. Four additional patients are omitted because of failure to obtain the test sample. The number of multiparae is again

TABLE VII

RESULTS OF TESTS FOR ANTIBODIES 4-6 MONTHS AFTER DELIVERY*

\begin{tabular}{l|c|c|c|c}
\hline & Negative & Weak & Coombs Positive & Total \\
\cline { 1 - 4 } Primiparae & 7 & 2 & 6 & 15 \\
Multiparae & 8 & 8 & 15 & 31 \\
\hline Total & & & & 46 \\
\hline
\end{tabular}

* The number out of 12,720 mothers with weak antibodies at delivery who were nevertheless treated. double that of the primiparae, a similar pattern to that observed in the whole group of 106 patients discussed above.

\section{The Risk of Immunization}

The following calculation is based on information on all the immunized mothers in Finland obtained from the four district laboratories responsible for the compulsory screening of all pregnant women. The figures for 1969 are the last not to have been influenced by the preventive programme. In 1969, altogether 165 newly immunized mothers were observed. This group includes 18 mothers with an Rh-negative child; the other children were $\mathrm{Rh}$ positive. In all the cases antibodies were detected four weeks before delivery and accordingly the group of 'late' antibody formers discussed above is not included.

The risk of immunization within six months of delivery in our control series was $3.5 \%$. Applying this to the figures obtained from the total number of births and parity distribution in 1969 with known gene frequencies of $\bar{D}$ and $\bar{d}$, we obtain the total number of $\mathrm{Rh}$-negative mothers delivering two consecutive children. This information is presented in Table VIII. These include all the children born to homozygous fathers and to a quarter of those born to heterozygous fathers. Also in Table VIII are the figures for the $\mathrm{Rh}$-negative mothers who gave birth to an Rh-negative child after an Rh-positive baby; this group represents one quarter of those children born of heterozygous fathers. In the last column of Table VIII is the number of observed newly immunized mothers delivered in 1969.

The expected and observed number of immunized mothers giving birth to an $\mathrm{Rh}$-negative child are close: 18 and $15 \cdot 8$, respectively. Conversely, there is a large surplus of observed immunized mothers giving birth to an Rh-positive child. The fact that the observed number is almost double that anticipated must depend on the secondary immune response. In other words, it seems that only about one half of the immunized mothers will be detected when the investigation is made six months after the last delivery.

\section{The Effect of Prevention on the Prevalence of Haemolytic Disease of the Newborn}

Although practically every Rh-negative mother delivering an Rh-positive child is protected now, the clinical effect of the programme on the number of new cases of immunization is far from its final goal. In order to estimate the proportion of mothers who 
TABLE VIII

DISTRIBUTION OF Rh IMMUNIZATION IN VARIOUS GROUPS OF Rh-NEGATIVE MOTHERS IN 1969 (THE LAST YEAR BEFORE PROPHYLAXIS BEGAN)

\begin{tabular}{|c|c|c|c|c|c|}
\hline Parity & $\%$ & $\begin{array}{c}\text { Rh-negative } \\
\text { Mothers }\end{array}$ & $\begin{array}{c}\text { Two Consecutive } \\
\text { Rh-positive Children }\end{array}$ & $\begin{array}{l}\text { One Rh-positive and } \\
\text { one Rh-negative Child }\end{array}$ & Total \\
\hline $\begin{array}{l}\text { II } \\
\text { III } \\
\text { IV } \\
\text { V } \\
\text { VI } \\
\text { Total }\end{array}$ & $\begin{array}{r}30 \cdot 41 \\
11 \cdot 28 \\
3.74 \\
0.95 \\
0.60 \\
100.00\end{array}$ & $\begin{array}{r}2406 \\
892 \\
296 \\
75 \\
47 \\
3716\end{array}$ & $\begin{array}{r}1311 \\
486 \\
161 \\
41 \\
26 \\
2025\end{array}$ & $\begin{array}{r}271 \\
100 \\
33 \\
8 \\
5 \\
417\end{array}$ & $\begin{array}{r}1582 \\
586 \\
194 \\
49 \\
31 \\
2442\end{array}$ \\
\hline \multicolumn{3}{|c|}{$\begin{array}{l}\text { Immunized } \\
\text { Expected }(3.5 \%) \\
\text { Observed }\end{array}$} & $\begin{array}{c}70 \cdot 9 \\
147\end{array}$ & $\begin{array}{l}14 \cdot 6 \\
18\end{array}$ & $\begin{array}{l}85 \cdot 5 \\
165\end{array}$ \\
\hline
\end{tabular}

Total births 67,500 , parity distribution as obtained from the present series, gene frequencies for $\overline{\mathrm{D}}, 0.6577$ and for $\overline{\mathrm{d}}, 0.3423$ with $43.26^{\circ}$ o DD, $45.03^{\circ}$, per Dd, and $11.27^{\circ}$ o dd. Risk of immunization, $3.5^{\circ}$, is obtained from the control series of 1967-68 (Table I).

deliver an Rh-positive child and who were not protected in connection with delivery of the next to last $\mathrm{Rh}$-positive child, the total number of mothers at risk is first calculated using the total number of births in each year, the parity distribution as well as the known proportion of homozygotes and heterozygotes in the population. The risk group is formed by all the Rh-negative mothers who give birth to two consecutive Rh-positive infants in each year. This condition is fulfilled in all children with homozygous $(43.26 \%)$ and in a quarter with heterozygous fathers $\left(\frac{1}{4}\right.$ of 45.03 or $\left.11.26^{\circ}{ }_{0}\right)$. In 1969 this group was $67,500 \times 0.1172 \times 0.5452 \times 0.4711$ (proportion of the multiparae) or 2032 .

In each year the number of mothers protected twice is compared with total group at risk. The result in periods of three months is presented in Fig. 1 which shows that in the last quarter one half $(47.6 \%)$ of the population at risk has still been delivered without protection in connection with the delivery of their former Rh-positive child. For comparison, the new cases of Rh-immunization observed between 1969 and 30 June 1972, are presented as a percentage of the 1969 figures. These are corrected according to the number of births, assuming that the parity distribution has remained unchanged.

\section{Discussion}

The immunization rate following a single pregnancy with an $\mathrm{ABO}$-compatible, $\mathrm{Rh}$-positive infant in the control series of approximately $1000 \mathrm{Rh}$ negative women was lower than in the series reported elsewhere and especially in England. The failure rate in our controlled trials is among the lowest so far reported. The recent report of the Collaborative RhoGAM study, however, shows that only 5 out of 3241 or $0.15 \%$ of the treated mothers de-

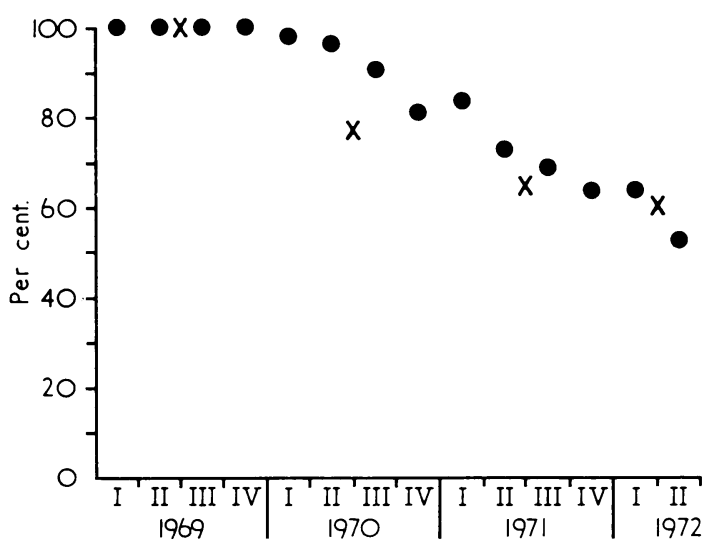

FIG. Percentage of Rh-negative mothers delivering an Rh-positive child where the mother was not protected after the last delivery but one. Crosses give the percentage of observed new cases of $\mathrm{Rh}$ immunization by year. These are derived from three sources, (1) those whose last delivery was before 1969 and were therefore not protected-presumably 'primed'; (2) true failures, and (3) 'failures', ie, immunization during the current pregnancy.

veloped anti-D (Fournal of Reproductive Medicine, 1971, p. 239). The higher failure rates reported elsewhere might depend on differences in the antibody detection at delivery. For example, in one centre only Coombs technique was used (fournal of Reproductive Medicine, 1971, p. 239). In such a series only some of the mothers with antibodies detectable by enzyme techniques would appear as failures of $\mathrm{Rh}$-prophylaxis in the post-partum investigation. In our series (see Table VII) there were in all 21 such cases out of $12,720(0 \cdot 16 \%)$ which would more than double the actual failure rate (Schneider, 1971). Whether this difference is real, eg, dependent on the difference in the number of high risk women, or due to chance only cannot be decided. Our control series was not followed up to 
estimate how many of the women developed antibodies due to the next pregnancy. This risk could, however, be studied in the national series of newly immunized Rh-negative mothers. It seems that approximately one half of the primed mothers do not form antibodies before the next pregnancy with an $\mathrm{Rh}$-positive infant, ie, the risk of immunization is doubled compared with the result of the postpartum sample. This concurs with results obtained elsewhere (Woodrow et al, 1971; Schneider, 1971).

In our series of treated mothers the great majority of failures appeared as a secondary immune response due to the next Rh-positive pregnancy, ie, $10 / 1027$ compared to $17 / 12,720$ or $1.0 \%$ and $0.13 \%$, respectively. The pattern of immunization thus seems to be different from that seen in untreated control series, where approximately half of the immunized mothers form antibodies after the first observed pregnancy, as reported by Ascari, Levine, and Pollack (1969) and Woodrow and Donohoe (1968), or calculated indirectly from the clinical series. With the very low failure rate $(0 \cdot 13 \%)$ in the post-delivery controls in the present series, the difference was more distinct than in other series reported from elsewhere (Schneider, 1971). However, the number of antibody producers due to a secondary stimulus is at least twice that in the controls after delivery. There is every reason, therefore, to increase the series with multiple pregnancies, a goal which enlarged our series far beyond the size needed for evaluation of the effect of prevention in the post-partum sample only. The incidence of $\mathrm{Rh}$-immunization by a single pregnancy before delivery was higher than the post-partum failure rate or $0.35 \%$ when estimated from the group of primiparae, but much lower than that reported from Canada (Bowman 1970). The fact that antibodies were present at delivery twice as frequently in the multiparae is difficult to explain without assuming that half of this group represents a primary and not a secondary response.

In the future, the different rates in primi- and multiparae should decrease and finally disappear when all mothers are treated. Still, primary immunization initiated during a single pregnancy forms a problem which seems to be at least as large as that of the dose effect. Although we have no experience of treatment before delivery, the importance of the series now in progress in Canada and Australia deserves emphasis.

Years ago, we used the ABO constellation as a marker to locate the pregnancy inducing the primary sensitization or, to use the old term, sensibilization (Nevanlinna, 1952 and 1953; Nevanlinna and Vainio, 1956). In the present series, the ABO con- stellation has some aspects of interest which might throw light on the mechanism of immunization as well as protection. We see once again in our control series that $\mathrm{ABO}$ incompatibility protects well against primary sensibilization and immunization, but gives poor if any protection to the mother against secondary stimulus (Woodrow, 1970). In the group immunized by a single pregnancy before delivery there was less $\mathrm{ABO}$ incompatibility among the primparae than among the multiparae. This is valid if antibodies in a part of the multiparae were in mothers already primed by the former (ABOcompatible) pregnancy. The lack of protection was even more striking in the 17 patients developing antibodies within six months of pregnancy: five were ABO-incompatible whereas only one out of 35 in the control series was found to have this constellation. In the group of patients immunized by the second pregnancy there were two such patients among the 10 failures. Although the figures are small, they indicate that the failures might well depend on factors other than the size of the transplacental haemorrhage and that they could not be prevented by enlarging the dose of anti-D immunoglobulin.

In a country like Finland with a very low birthrate, the clinical effect of prevention is slow. In three and a half years half of the mothers at risk have still not received anti-D immunoglobulin in connection with the delivery of the next to last Rh-positive child. The curve illustrating the development of the protection, ie, the Rh-negative mothers who delivered the last Rh-positive child without protection, is S-shaped and will finally reach the level formed by the number of failures. Approximately half of the protected mothers will give birth to an additional child. The frequency of postpartum failures $(0.13 \%)$ will result in delivery by about six such mothers each year. The group of failures emerging during the next pregnancy is larger than this. Out of some 2000 mothers at risk approximately 0.7 will form antibodies each year, ie, some 14 mothers. The last group of failures or those who form antibodies by a single pregnancy before the delivery was in the present series $0.35 \%$ of all $\mathrm{Rh}$-negative mothers delivering an Rh-positive child or, given in figures, some 15 additional mothers. This group consists of the 'late' antibody formers and is consequently of minor clinical importance.

For the near future the incidence of HDN as a clinical and therapeutical problem will dependapart from the failures discussed above- on the number of mothers who are already immunized and deliver additional children with haemolytic disease 
of the newborn. In Finland, with a liberal abortion law, this group has formerly been between approximately one half and two thirds of the new cases of immunization, eg, 98 out of 165 in 1969.

The present results show that more complete protection can be expected only by starting a programme of ante-partum $\mathrm{Rh}$ prophylaxis for all $\mathrm{Rh}$-negative women at risk. There is no doubt that this approach is justified as a clinical trial in as many research centres as possible to obtain the data required to determine the timing and dosage of anti-D IgG given during pregnancy.

\section{REFERENCES}

Ascari, W. Q., Levine, P., and Pollack, W. P. (1969). Incidence of maternal $\mathrm{Rh}$ immunization by $\mathrm{ABO}$ compatible and incompatible pregnancies. British Medical fournal, 1, 399-401.

Bowman, J. M. (1970). Prevention of haemolytic disease of the newborn. British fournal of Haemalology, 19, 653-655.

Bowman, J. M., Chown, B., Lewis, M., Kaita, H., Peddle, L. J., and Pollock, J. M. (1969). Rh immunization of primagravidae. Pediatric Research, 3, 375-376.

Buchanan, D. I., Bell, R. E., Beck, R. P., and Taylor, W. C. (1969). Use of different doses of anti-Rh IgG in the prevention of $\mathrm{Rh}$ isoimmunization. Lancet, 2, 288-290.

Clarke, C. A. (1972). Blood group incompatibility between mother and foetus. Clinical Science, 43, 1-11.

Clarke, C. A. and McConnell, R. B. (1972). Prevention of Rhhemolytic Disease. Charles C. Thomas, Springfield, Illinois.
Combined Study from Centres in England and Baltimore (1971). Prevention of Rh-haemolytic disease: final results of the 'highrisk' clinical trial. British Medical fournal, 2, 607-609.

Godel, J. C., Buchanan, D. I., Jarosch, J. M., and McHugh, M. (1968). Significance of Rh-sensitization during pregnancy. British Medical fournal, 4, 479-482.

Fournal of Reproductive Medicine (1971). Current problems in prophylactic treatment of $\mathrm{Rh}$ erythroblastosis. Fournal of Reproductive Medicine, 6, 232-255.

Nevanlinna, H. R. (1952). Factors affecting maternal Rh immunisation. Preliminary report. Acta Pathologica et Microbiologica Scandinavica, Suppl. no. 93, 402-410.

Nevanlinna, H. R. (1953). Factors affecting maternal Rh immunisation. Annales Medicinae Experimentalis et Biologiae Fenniae, 31, Suppl. no. 2.

Nevanlinna, H. R. and Vainio, T. (1956). The influence of mother child $\mathrm{ABO}$ incompatibility $\mathrm{Rh}$ immunisation. Vox Sanguinis, 1, 26-36.

Schneider, J. (1971). Tagungsberichte. IV Arbeitstagung zur Prophylaxe der Rhesus-sensibilisierung mit Immunglobulinanti-D. Geburtshilfe und Frauenheilkunde, 31, 493-522.

Woodrow, J. C. (1970). Rh immunisation and its prevention. Series Haematologica, 3, No. 3.

Woodrow, J. C., Clarke, C. A., McConnell, R. B., Towers, S. H., and Donohoe, W. T. A. (1971). Prevention of Rh-haemolytic disease: results of the Liverpool 'low-risk' clinical trial. British Medical fournal, 2, 610-612.

Woodrow, J. C. and Donohoe, W. T. A. (1968). Rh-immunization by pregnancy: results of a survey and their relevance to prophylactic therapy. British Medical fournal, 4, 139-144.

WHO Scientific Group (1971). Prevention of Rh Sensitization. World Health Organization. Technical Report Series, no. 468. World Health Organization, Geneva.

Zipursky, A. and Israels, L. G. (1967). The pathogenesis and prevention of $\mathrm{Rh}$ immunization. Canadian Medical Association fournal, 97, 1245-1257. 